\title{
Clinical and Bacteriological Profile of Neonatal Septicaemia at A Community Level Medical College Hospital
}

\author{
ASMNU AHMED $^{\mathrm{a}}$, MI PERVEZ ${ }^{\mathrm{b}}$, BK PAUL $^{\mathrm{c}}$, KK BISHWAS ${ }^{\mathrm{d}}$
}

Summary:

Septicaemia is a significant cause of morbidity and mortality in neonates. Meningitis is a serious problem in newborns with high mortality and frequent neurological sequelae. In neonates, signs and symptoms of infections are often obscure and clinical examination cannot distinguish septicaemic babies with or without meningitis. Therefore, lumbar puncture is often not done in time and thus diagnosis of meningitis is missed. Our aim was to see the association of bacterial meningitis in neonatal septicaemia and their clinical and bacteriological profile. This study was performed at the neonatal ward of Kumudini Women's Medical College Hospital from August 2007 to July 2009. All admitted newborns diagnosed as septicaemia clinically were enrolled prospectively. Detailed history was taken, thorough clinical examination performed, and blood culture, CSF study and other relevant investigations were done. Patients received standard medical care and followedup daily till discharge/death. Among 86 suspected cases, 30 (34.9\%) had positive blood culture. Common clinical presentations of culture-positive cases were poor feeding (86.7\%), lethargy (70\%), respiratory distress (56.7\%), fever

Introduction:

The World Health Organization (WHO) estimates that 4 million neonatal deaths occur around the world every year ${ }^{1}$. Approximately $98 \%$ of these deaths occur in developing countries, and are attributable to infections, asphyxia, and consequences of prematurity and low birth

a. Dr. A.S.M. Nawshad Uddin Ahmed, FCPS, Associate Professor, Bangladesh Institute of Child Health, Dhaka Shishu Hospital

b. Dr. Md. Imtiaz Pervez, DCH, Registrar of Paediatrics, Kumudini Women's Medical College, Mirzapur, Tangail

c. Dr. Bijoy Kumar Paul, MBBS, Medical Officer, Kumudini Hospital, Mirzapur, Tangail

d. Dr. Kishore Kumar Bishwas, MBBS, Medical Officer, Kumudini Hospital, Mirzapur, Tangail

Address of Correspondence: Dr. A.S.M. Nawshad Uddin Ahmed, FCPS, Associate Professor, Bangladesh Institute of Child Health, Dhaka Shishu Hospital, Sher-e-Bangla Nagar, Dhaka-1207, Cell: 01552-372200, E-mail: dr_nawshad@yahoo.com

Received: 24 May 2010

Accepted: 29 October 2010
(46.7\%), jaundice (33.3\%), seizure (26.7\%) and cyanosis (20\%). Male child outnumbered the baby girls (1.7:1). Other risk factors were maternal fever during delivery, prolonged rupture of membranes, birth asphyxia and poor socioeconomic status. Majority (63.3\%) of the cultures isolated gram-negative bacilli, most commonly Klebsiella pneumonia (16.7\%), Pseudomonas sp. (16.7\%), and Acinetobacter (10\%). Staphylococcus aureus (20\%) was most common among gram-positive organisms, followed by Streptococcus pneumoniae (10\%); no Group B streptococcus was isolated. Associated meningitis was present in two cases (6.7\%) and nine out of 30 culturepositive cases (30\%) died. This study confirms that neonatal septicaemia is a major problem in perinatology with high case fatality. As associated meningitis is difficult to distinguish clinically, CSF study needs to be included in septicaemia screening. An alarming finding of the study is that high proportion of the organisms are resistant to most of the commonly used antibiotics, again emphasize the importance of judicious antibiotic use.

(J Bangladesh Coll Phys Surg 2011; 29: 143-150)

weight ${ }^{2}$. Overall, neonatal mortality accounts for nearly two-thirds of infant mortality and one-third of underfive childhood mortality worldwide ${ }^{3-5}$. Serious bacterial infections are major contributors to newborn morbidity and mortality. An estimated $20 \%$ of all children born in developing countries, or 30 million annually develop an infection during the neonatal period, and infectious diseases account for an estimated one-third of all neonatal deaths ${ }^{1,6}$.

Meningitis is a serious problem in newborn infants with a high mortality and frequent neurological sequelae in survived patients. About $20-30 \%$ of neonatal septicaemia, whether early or late, is complicated by bacterial meningitis ${ }^{7,8}$. One study from Saudi Arabia showed 21 per 1000 admission at NICU had bacterial meningitis ${ }^{9}$. In a two-year (1985-87) prospective study of acute meningitis in England and Wales in infants; the incidence of neonatal meningitis was 0.32 per 1000 live 
births $^{10}$, another study done in Oxford showed 0.38 per 1000 live births ${ }^{11}$. Reviews from USA, ${ }^{7,12}$ Europe $^{10,13}$ and Australia ${ }^{14}$ have shown $0.2-0.5$ cases of bacterial meningitis per 1000 live births. In our country we do not have much data, but two prospective studies done at Dhaka Shishu Hospital have shown that $13-27 \%$ of neonates with septicaemia had concurrent meningitis ${ }^{15,16}$.

Several studies report that prematurity, low birth weight, prolonged rupture of membranes and maternal infections are most common perinatal factors associated with septicaemia and meningitis in the newborn period $^{7,8,12,13,17}$. Clinical examination cannot distinguish septicaemic babies with meningitis from those without meningitis. Blood culture may also be negative in meningitis. One study showed $13 \%$ of bacterial meningitis with positive CSF culture had negative blood culture ${ }^{13}$, another study showed 15\% case of meningitis with negative blood culture ${ }^{18}$.

The causative agents of neonatal septicaemia and meningitis vary between geographical areas and with time in any particular locality. To our knowledge, there has been no documented survey on causative agents of neonatal septicaemia and meningitis at community level from our country. During 1975-91, the leading causes of neonatal bacterial meningitis were Group B streptococcus (34.1\%) and Escherichia coli (28.5\%), which accords with the patterns of causative organisms reported from UK ${ }^{10}$, USA ${ }^{19}$ and Australia. ${ }^{14}$ Another study done at Saudi Arabia shows Klebsiella pneumoniae and Serratia marcescens as the important organisms of neonatal meningitis ${ }^{9}$. In North America and Europe, the prevalent bacterial agents of late-onset septicaemia include coagulase negative staphylococcus, Klebsiella sp. and Escherichia coli. ${ }^{20}$ The two studies done at Dhaka Shishu Hospital showed Escherichia coli, Klebsiella pneumonia and Pseudomonas aeruginosa as the common organisms of neonatal septicaemia and meningitis ${ }^{15,16}$.

\section{Materials and methods:}

Study site: This hospital based prospective study was conducted at the neonatal ward of Kumudini Hospital in a cohort neonates admitted between August 2007 and July 2009. Kumudini Hospital is a 70 years old, 750beded non-profit private hospital, with laboratory and radiology facilities in Mirzapur, a rural sub-district
(Thana) of Bangladesh, located $60 \mathrm{~km}$ north of Dhaka. Mirzapur has an estimated total population of 400,000, distributed in 13 unions and 219 villages. The hospital is staffed by specialists of all disciplines. A medical college, Kumudini Women's Medical College, is affiliated to the hospital. As the major referral hospital, Kumudini Hospital serves most patients throughout the Mirzapur sub-district.

Study Population: All admitted newborns diagnosed as septicaemia clinically on admission or at any stage of hospitalization were considered for enrolment. Septicaemia was suspected based on the presence of one or more clinical sign consistent with possible serious bacterial infection including lethargy, refusal of feeds, abdominal distension, vomiting, groaning, grunting, facial grimace, respiratory distress, hypothermia, hyperthermia or sclerema with or without supporting evidence of risk factors such as prematurity, low birth weight (LBW), birth asphyxia, maternal chorioamnionitis (maternal fever and/or foul smelling vaginal discharge) and prolonged rupture of membranes. Meningitis was suspected from a history of irritability, convulsions, high-pitched cry and full, tense anterior fontanel along with other features of septicaemia. We excluded babies in moribund condition and those who had active bleeding for which lumbar puncture could not be done.

Babies were categorized according to the following risk factors for septicaemia: birth weight ( $<1500$ g, $1500-$ 2500 g, $>2500$ g), gestational age ( $<37$ weeks, $37-42$ weeks, $>42$ weeks), birth-place (home, hospital/clinic), and mode of delivery (normal, forceps-assisted, Caesarean section). Study patients were also categorized as having early- or late-onset septicaemia depending upon whether the onset of symptoms was within 7 days (early-onset) or 8 to 28 days of life (late-onset).

After enrolment, patients underwent the following diagnostic procedures: complete blood count, blood culture, CSF study (cytology, biochemistry and culture) and other relevant investigations as necessary. A diagnosis of definitive septicaemia was made when the clinical suspicion was confirmed by a positive blood culture. Similarly bacterial meningitis was diagnosed depending on clinical suspicion and positive CSF culture. Of the total 86 cases evaluated during the study period, 30 had a positive blood culture; 2 of them also 
had positive CSF culture. The presenting symptoms and signs, agents of infection and outcome of the 30 culture positive cases are described here.

Culture methods: A blood sample was taken from each patient with suspected septicaemia after careful preparation of the skin site with 70\% isopropyl alcohol. The site chosen was a peripheral vein, preferably the antecubital vein. Blood ( 2 ml) was withdrawn using a sterile disposable syringe and transferred using sterile technique to $5 \mathrm{ml}$ of Tripticase Soy broth. In the laboratory, subculture was done on days 1, 2, 3 and 5 of incubation onto blood agar, chocolate agar and MacConkey's media. Cerebrospinal fluid was plated on the same media as the blood. Antimicrobial sensitivity testing of all isolates was performed on Muller Hinton Agar (MHA) plates by the Kirby Bauer diffusion method.

Patient management: All patients received the standard treatment for neonatal septicaemia followed in the hospital. Cefotaxime and gentamicin were started at enrolment and changed later, if needed, depending on the culture sensitivity report as well as the clinical condition. Other supportive therapy such as correction of acidosis, maintenance of fluid and electrolyte balance, ventilatory assistance, phototherapy and blood transfusion was given as required. Infants enrolled in the study were evaluated on a daily basis while hospitalized.

Data collection: At enrolment a detailed history was taken and thorough physical examination was performed and recorded on standard forms. The parents of the neonates were explained about the study and then witnessed verbal consent was taken.

Statistical analysis: The data were subjected to statistical analysis according to standard procedure. SPSS version 12.0 for Windows (SPSS Inc, Chicago, IL, USA) software was used for data recording and analysis. Results of the findings were verified by conducting standard tests for significance, including unpaired student T-test and Chisquare $\left(\mathrm{c}_{-}^{2}\right)$ tests, as appropriate. A p-value of $<0.05$ was considered as statistically significant.

\section{Results:}

Among 86 cases of clinically suspected neonatal septicaemia, 30 (34.9\%) had a positive blood culture; 12 (40\%) had early- and 18 (60\%) late-onset infection. Blood culture positivity was significantly lower in those with early- $(25.5 \%, 12 / 47)$ compared to late-onset $(46.1 \%, 18 / 39)$ disease $(\mathrm{p}<0.05)$. Although males with positive blood cultures $(63.3 \%, 19 / 30)$ outnumbered females $(36.7 \%, 11 / 30)$, there were no gender differences in culture positivity rate (males 32.7\%, 19/ 58 ; females $(39.3 \%, 11 / 28)$ or proportion of early(males 42.1\%, 8/19; females 36.4\%, 4/11) and late-onset (males 57.9\%, 11/19; females 63.6\%, 7/11) disease. Forty percent of neonatal septicaemia cases were preterm and 18 (60\%) were term babies. Blood culture positivity rate was equivalent, however, for preterm (30.0\%, 12/40) and term (39.1\%, 18/46) infants; and for very LBW (30.8\%, 4/13), LBW (36.8\%, 14/38) and normal birth weight $(34.3 \%, 12 / 35)$ infants. (Table I).

Table-I

\begin{tabular}{|c|c|c|c|c|c|c|}
\hline \multicolumn{7}{|c|}{ Blood culture-positivity and mortality rates of sub-categories of neonates with suspected sepsis $(n=30)$} \\
\hline \multicolumn{2}{|l|}{ Category } & $\begin{array}{c}\text { Number } \\
\text { enrolled } \\
\text { cultures (n) }\end{array}$ & $\begin{array}{c}\text { Positive } \\
\text { blood } \\
\text { positivity (\%) }\end{array}$ & $\begin{array}{l}\text { Blood } \\
\text { culture }\end{array}$ & $\begin{array}{l}\text { Mortality } \\
\text { (n) }\end{array}$ & $\begin{array}{c}\text { Mortality (\% } \\
\text { of blood culture } \\
\text { positive cases) }\end{array}$ \\
\hline \multirow[t]{2}{*}{$\overline{\text { Onset }}$} & Early & 47 & 12 & 25.5 & 3 & 25.0 \\
\hline & Late & 39 & 18 & 46.1 & 6 & 33.3 \\
\hline \multirow[t]{2}{*}{ Gender } & Male & 58 & 19 & 32.7 & 6 & 31.6 \\
\hline & Female & 28 & 11 & 39.3 & 3 & 27.3 \\
\hline \multirow[t]{2}{*}{ Gestational age } & Pre-term & 40 & 12 & 30.0 & 4 & 33.3 \\
\hline & Term & 46 & 18 & 39.1 & 5 & 27.8 \\
\hline \multirow[t]{3}{*}{ Birth weight (g) } & $<1,500$ & 13 & 4 & 30.8 & 2 & 50.0 \\
\hline & $1,500-2,500$ & 38 & 14 & 36.8 & 4 & 28.6 \\
\hline & $>2,500$ & 35 & 12 & 34.3 & 3 & 25.0 \\
\hline \multirow{3}{*}{$\begin{array}{l}\text { Monthly } \\
\text { income (Tk.) }\end{array}$} & $<5,000$ & 50 & 16 & 32.0 & 5 & 31.2 \\
\hline & $5,000-10,000$ & 25 & 9 & 36.0 & 3 & 22.2 \\
\hline & $>10,000$ & 11 & 5 & 45.4 & 1 & 20.0 \\
\hline
\end{tabular}


Majority of the deliveries of septicaemic neonates in this study were conducted at home (70\%, 21/30) and 9 (30\%) took place in a hospital or clinic. Five culture positive cases $(16.7 \%)$ were delivered by caesarean section, and 11 (36.7\%) had a history of birth asphyxia. Neonates with septicaemia more often were from low socio-economic classes (family income $<5,000$ Taka per month) $(53.3 \%, 16 / 30)$ than middle $(5,000$ to 10,000 Taka) $(30 \%, 9 / 30)$ or higher income (> 10,000 Taka) (16.7\%, 5/30) groups. There was a trend for the culture positivity rate to be lower in the low $(32 \%, 16 / 50)$ than the middle $(36 \%, 9 / 25)$ or high $(45.4 \%, 5 / 11)$ income groups, although the difference was not significant statistically. (Table I) Prolonged rupture of membranes for more than 18 hours was present in 20\% (6/30) cases and maternal fever during delivery in 10\% (3/30), one of them had both (4\%).

The most frequent clinical presentations of patients with culture-proven serious neonatal bacterial infection were poor feeding (86.7\%, 26/30), lethargy (70\%, 21/30), respiratory distress $(56.7 \%, 17 / 30)$, fever $(46.7 \%, 14 /$ $30)$, jaundice (33.3\%, 10/30), seizure (26.7\%, 8/30) and cyanosis (20\%, 6/30). Jaundice and convulsion were more common in early-onset and fever was more common in late-onset disease, though not statistically significant ( $\mathrm{p}>0.05$ ); other presenting signs were almost similar in both groups. (Table II) Meningitis cases were presented with features of septicaemia; there were no specific symptoms or signs related to meningitis.
Of the 30 organisms isolated, about two-thirds (63.3\%, 19/30) were gram-negative bacilli; 11 (36.7\%) were gram-positive. Among the gram-negative bacilli, Klebsiella pneumonia (16.7\%, 5/30), Pseudomonas sp. (16.7\%, 5/30), and Acinetobacter (10\%, 3/30) was the most common and Staphylococcus aureus (20\%, 6/30) and Streptococcus pneumoniae $(10 \%, 3 / 30)$ was most common among gram-positive organisms, The pattern of organisms isolated was similar, regardless of time of onset of disease, birth weight or gestational age. (Table III) A large number of the organisms are resistant to all of the commonly used antibiotics. Ampicillin virtually has no effect except against Streptococcus pneumoniae and $H$. influenza. Gentamicin, third generation cephalosporins and ciprofloxacin showed mixed sensitivity pattern. Imipenem and netilmicin are found most effective against majority of the organisms. (Table IV).

Of the 30 culture-positive cases, 9 (30\%) died. The case fatality rate was inversely related to birth weight $(<1500$ g: 50\%, 2/4; 1500-2500 g: 28.6\%, 4/14; >2500 g: 25\%, $3 / 12)$, and was highest in neonates infected with $E$. coli (50\%), followed by Klebsiella pneumoniae and Pseudomonas sp. (40\%) and no mortality in neonates infected with $H$. influenza, Streptococcus sp, Enterobacter and Salmonella sp. (Fig. I) Case fatality was not influenced by time of onset (early-onset: 25\%, 3/12; late-onset: $33.3 \%, 6 / 18$ ) or gender (males: $31.6 \%$, 6/19, females: 27.3\%, 3/11). (Table I).

Table-II

Common Clinical Manifestations of the Blood Culture Positive Cases of Neonatal Septicaemia $(n=30)$

\begin{tabular}{|c|c|c|c|c|}
\hline \multirow[t]{2}{*}{ Clinical features } & \multicolumn{3}{|c|}{ Prevalence (\%) } & \multirow[t]{2}{*}{ p-value } \\
\hline & All & Early-onset & Late-onset & \\
\hline Poor feeding & 86.7 & 91.7 & 83.3 & NS \\
\hline Lethargy & 70.0 & 66.7 & 72.2 & NS \\
\hline Respiratory distress & 56.7 & 66.7 & 50.0 & NS \\
\hline Fever & 46.7 & 33.3 & 55.6 & NS \\
\hline Jaundice & 33.3 & 41.7 & 27.8 & NS \\
\hline Seizure & 26.7 & 41.7 & 16.7 & NS \\
\hline Cyanosis & 20.0 & 16.7 & 22.2 & NS \\
\hline Vomiting & 13.3 & 16.7 & 11.1 & NS \\
\hline Hypothermia & 10.0 & 16.7 & 5.6 & NS \\
\hline Apnoea & 10.0 & 16.7 & 5.6 & NS \\
\hline
\end{tabular}

NS=Non-significant 


\section{Table-III}

\begin{tabular}{|c|c|c|c|c|c|c|c|c|}
\hline \multicolumn{9}{|c|}{ Organisms Isolated in Relation to Onset of Disease, Birth Weight and Gestational Age $(n=30)$} \\
\hline \multirow[t]{2}{*}{ Organisms } & \multirow{2}{*}{$\begin{array}{c}\text { Total } \\
\text { (percentage) }\end{array}$} & \multicolumn{2}{|c|}{ Age of onset } & \multicolumn{3}{|c|}{ Birth weight (g) } & \multicolumn{2}{|c|}{ Gestational age } \\
\hline & & Early & Late & $<1500$ & $1500-2500$ & $>2500$ & Pre-term & Term \\
\hline Staphylococcus aureus & $6(20.0)$ & 2 & 4 & 1 & 2 & 3 & 3 & 3 \\
\hline Klebsiella pneumoniae & $5(16.7)$ & 2 & 3 & - & 3 & 2 & 1 & 4 \\
\hline Pseudomonas sp. & 5 (16.7) & 1 & 4 & 1 & 2 & 2 & 1 & 4 \\
\hline Acinetobacter & $3(10.0)$ & 1 & 2 & 1 & 1 & 1 & 2 & 1 \\
\hline Streptococcus pneumoniae & $3(10.0)$ & 2 & 1 & - & 2 & 1 & 1 & 2 \\
\hline Streptococcus sp. & $2(6.7)$ & - & 2 & - & 1 & 1 & 1 & 1 \\
\hline Haemophilus influenzae & $2(6.7)$ & 1 & 1 & - & 1 & 1 & 1 & 1 \\
\hline Escherichia coli & $2(6.7)$ & 1 & 1 & - & 1 & 1 & 1 & 1 \\
\hline Enterobacter sp. & $1(3.3)$ & 1 & - & 1 & - & - & 1 & - \\
\hline Salmonella sp. & $1(3.3)$ & 1 & - & - & 1 & - & - & 1 \\
\hline Total & $30(100)$ & 12 & 18 & 4 & 14 & 12 & 12 & 18 \\
\hline
\end{tabular}

Table-IV

Antibiotic Resistance (\%) of Organisms Isolated ( $n=30)$

\begin{tabular}{lcccccccccc} 
Antibiotic & $\begin{array}{c}\text { Staph. } \\
\text { aureus }\end{array}$ & $\begin{array}{c}\text { Kl. pneu- } \\
\text { moniae } \\
(\mathrm{n}=6)\end{array}$ & $\begin{array}{c}\text { Pseudo- } \\
\text { monassp. } \\
(\mathrm{n}=5)\end{array}$ & $\begin{array}{c}\text { bacter } \\
(\mathrm{n}=5)\end{array}$ & $\begin{array}{c}\text { moniae } \\
(\mathrm{n}=3)\end{array}$ & $\begin{array}{c}\text { coccus } \\
(\mathrm{n}=3)\end{array}$ & $\begin{array}{c}\text { H. influ- } \\
\text { enzae }(\mathrm{n}=2)\end{array}$ & $\begin{array}{c}\text { E. coli } \\
(\mathrm{n}=2) \\
(\mathrm{n}=2)\end{array}$ & $\begin{array}{c}\text { Entero- } \\
\text { bacter sp. } \\
(\mathrm{n}=1)\end{array}$ & $\begin{array}{c}\text { Salmo- } \\
\text { nella sp. } \\
(\mathrm{n}=1)\end{array}$ \\
\hline Ampicillin & 83.3 & 100 & 100 & 100 & 0 & 50 & 0 & 50 & 100 & 100 \\
Gentamicin & 16.7 & 60 & 80 & 66.7 & 0 & 0 & 0 & 0 & 0 & 0 \\
Cefotaxime & 16.7 & 60 & 80 & 33.3 & 0 & 0 & 0 & 0 & 0 & 100 \\
Ceftriaxone & 16.7 & 60 & 60 & 33.3 & 0 & 50 & 0 & 0 & 0 & 100 \\
Ceftazidime & 33.3 & 20 & 40 & 33.3 & 0 & 0 & 0 & 0 & 0 & 100 \\
Ciprofloxacin & 16.7 & 40 & 40 & 33.3 & 0 & 0 & 0 & 0 & 0 & 100 \\
Imipenem & 0 & 0 & 20 & 0 & 0 & 0 & 0 & 0 & 0 & 0 \\
Netilmicin & 0 & 0 & 60 & 0 & 0 & 0 & 0 & 0 & 0 & 0 \\
\hline
\end{tabular}

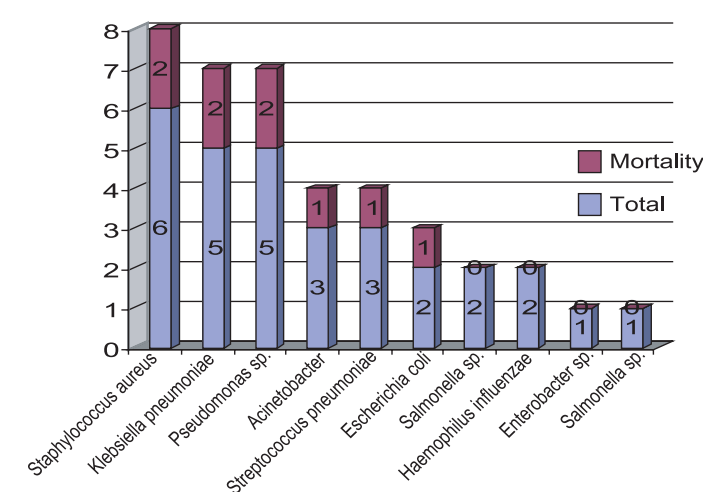

Fig.-1. Mortality of the 30 Blood Culture Positive Cases of Neonatal Septicaemia in Relation to Bacterial pathogens. (Total no of deaths $n=9$ )
Of the 30 culture-positive cases, 2 also had meningitis with culture-positive CSF; among them, 1 patient (50\%) died. Streptococcus pneumoniae caused meningitis in early-onset and Klebsiella pneumoniae in late-onset disease.

\section{Discussion:}

In this study, at a community level medical college hospital in Bangladesh, we found that late-onset neonatal septicaemia was more common than early-onset disease; in contrast to other reports in which early-onset septicaemia generally has been more common ${ }^{21,22}$. Perhaps this discrepancy is due to the fact that mortality in early-onset cases is relatively high ${ }^{23}$, and thus, some 
neonates in the catchment area of our hospital, which largely serves a low socioeconomic status community with poor communication facilities, might have died prior to arrival at the hospital. Although males have been reported to be 2- to 6-fold more likely than females to develop septicaemia ${ }^{23,24}$, the 1.7:1 ratio of male-tofemale infants in our study, while seemingly consistent with this data, could also reflect a gender bias in presentation to the hospital for care. Population-based studies would be needed to address this important question. The clinical features, culture positivity rates, and case fatality rates, however, were equivalent across gender, suggesting that the males and females in the study overall had a similar degree of illness.

The majority of the study population was poor, and delivered at home, largely in the hands of untrained birth attendants. Home deliveries are common in Bangladesh $^{25}$, and typically are conducted in poor standards of asepsis ${ }^{26}$. History of unclean vaginal examination was associated with a $10 \%$ incidence of deep infection in one study ${ }^{27}$. Home deliveries also are significantly related to birth asphyxia ${ }^{28}$, which was highly prevalent in our study population, and which, in turn, is associated with an increased risk of serious neonatal infection ${ }^{29}$.

The clinical features of neonatal septicaemia seen in this series are similar to those previously reported in other studies ${ }^{30,31}$. In majority of cases early clinical presentation was nonspecific simulating other common neonatal problems. Poor feeding was present in majority of the cases (86.7\%). Other common presentations were lethargy (70\%), respiratory distress (56.7\%), fever (46.7\%), jaundice (33.3\%), seizure (26.7\%) and cyanosis (20\%). Jaundice and convulsion were more common in early-onset and fever in late-onset disease, though the difference was not statistically significant ( $>>0.05$ ); other presenting signs were almost similar in two groups. Apnoea and hypothermia was mostly seen in preterm babies. The more non-specific symptomatology of disease and the relatively greater tendency to over-diagnose illness in the younger age group may have contributed to the lower percentage of positive cultures in neonates with early- compared to late-onset disease. Nonetheless, negative blood culture does not rule out septicaemia. Squire et $\mathrm{al}^{32}$. reported 7 cases with negative culture, fatal outcome and postmortem evidence of infection. The possibility of infection with anaerobes also cannot be ruled-out as anaerobic culture was not performed in this series. Chow et $\mathrm{al}^{33}$. reported that $26 \%$ of all neonatal septicaemia was caused by anaerobes.

Of the organisms isolated 19 (63.3\%) were gram negative and the rest $(11,36.7 \%)$ gram positive. Increasing prevalence of gram negative septicaemia has been reported from other studies in India ${ }^{34,35}$ and Pakistan ${ }^{23,36}$ as well as previous studies in our country ${ }^{15,16,37}$. Earlier study showed prevalence of $E$. coli, followed by Klebsiella pneumonia and Pseudomonas sp., ${ }^{15}$ later studies showed preponderance of Klebsiella, followed by Pseudomonas sp. and Acinetobacter ${ }^{16,37}$. In the present study, Klebsiella pneumonia was also the most prevalent organism (16.7\%), followed by Pseudomonas sp. (16.7\%) and Acinetobacter (10\%) and only 2 (6.7\%) E. coli. This supports the changing trend of bacterial etiology in neonatal septicaemia ${ }^{38}$. Group B Streptococcus was not isolated in this study, unlike western, developed countries where it is the major agent of neonatal septicaemia $21,22,39$ The insignificance of GBS as a pathogen in many developing countries is supported by a number of other studies $34,40-46$. This may be attributable to low prevalence of GBS colonization of pregnant mothers in this area, or, possibly, to the presence of strains with low virulence ${ }^{47}$.

An alarming finding in this study is the high proportion of the organisms are resistant to all of the commonly used antibiotics. Imipenem and netilmicin are found most effective against majority of the organisms. Gentamicin, third generation cephalosporins and ciprofloxacin, which previously had good sensitivity, also becoming resistant. This observation shows that the problem of antibiotic resistance is a serious threat for treating serious bacterial infections in neonates and to control antibiotic resistance, practice of prudent or judicious use of antibiotics is very important.

The present survey confirms the high case fatality rate in neonatal septicaemia, despite care in a medical college hospital and use of appropriate antimicrobial therapy. The death rate was higher in preterm LBW, highlighting the importance of anticipatory guidance for parents at home, particularly those with a LBW infant, and early clinical suspicion on the part of practitioners. The survey also showed epidemiological features of neonatal 
septicaemia that may have direct future preventive measures. But due to small sample size the study identified the need for continuing evaluation at different levels of local patterns and antibiotic sensitivities of pathogens of neonatal septicaemia to formulate rational antibiotic policy. There also is a need for communitybased case-control studies with larger sample sizes to identify risk factors and preventive measures for neonatal septicaemia.

\section{Conclusion:}

The present survey confirms that neonatal septicaemia is a major problem in perinatology and paediatric infectious disease with high case fatality. To identify risk factors for adverse outcome and preventive measures, case-control studies with representative sample size is recommended. High incidence of antibiotic resistance amongst the various organisms again emphasizes the importance of judicious antibiotic use.

\section{Acknowledgements:}

The study was supported by a research grant from Bangladesh College of Physicians and Surgeons (BCPS) under Health, Nutrition and Population Sector Programme (HNPSP). We like to thank the families who participated in the study, doctors and nurses of the Department of Paediatrics who were very much helpful during the study, Dhaka Shishu Hospital/ICDDR,B Microbiology Research Laboratory at Kumudini Hospital for doing the cultures (Blood \& CSF) free of cost for the study and the administration of Kumudini Hospital for giving permission to conduct the study and its publication.

\section{References:}

1. World Health Organization. Perinatal mortality. A listing of available information. Geneva, WHO 1996:32-6. (WHO/ FRH/MSM/96.7).

2. Black RE, Moris SS, Bryce J. Where and why are 10 million children dying every year? Lancet 2003; 361: 2226-34.

3. World Health Organization. Mother-baby package: implementing safe motherhood in countries. Maternal Health and Safe Motherhood Programme. Geneva, WHO 1994. (WHO/FHE/MSM/94.11).

4. Saving Newborn Lives. State of the World's Newborns. Save the Children Federation 2001; 1-49. Available from: www.savethechildren.org/publications/newborns_report.pdf. Accessed: 27 June 2010.
5. World Health Organization. Management of sick newborn. Report of a Technical Working Group, Ankara. Available from: http://www.helid.desastres.net/en/d/Js2891e/. Accessed: 27 June 2010.

6. Stoll BJ. The global Impact of neonatal infection. Clin Perinatol 1997; 24: 1-21.

7. Issacs D, Moxon ER. Neonatal infections. Oxford: Butterworth-Heineman 1991: 57.

8. De Louvois J, Harvey D. Infections in the newborn. London: John Wiley and Sons 1990: 107-15.

9. Al Harthi AA, Dagriri KA, Asindi AA, Bello CS. Neonatal meningitis. Saudi Medical Journal 2000; 21: 550-3.

10. De Louvois J, Blackbourn J, Hurley R, Harvey D. Infantile meningitis in England and Wales: a two years study. Arch Dis Child 1991; 66: 603-7.

11. Hristeva L, Booy R, Bowler I, Wilkinson AR. Prospective surveillance of neonatal meningitis. Arch Dis Child 1993; 69: 14-8.

12. Overall JC. Neonatal bacterial meningitis. J Paediatr 1970; 76: 499-511.

13. Bell AH, Brown D, Halliday HL, McClure G, Reid MMc. Meningitis in the newborn - a 14-years review. Arch Dis Child 1989; 64: 873-4.

14. Francis BM, Gilbert GL. Survey of neonatal meningitis in Australia 1987-89. Med J Aust 1992; 156: 177-84.

15. Ahmed ASMNU, Chowdhury MAKA, Haque M, Darmstadt GL. Clinical \& bacteriological profile of neonatal septicaemia in a tertiary level paediatric hospital in Bangladesh. Ind Paediatr 2002; 39: 1034-9.

16. Haque MM, Ahmed ASMNU, Chowdhury MAKA, Darmstadt GL, Saha SK. Septicaemic neonates without lumber puncture: what are we missing? J Trop Paediatr 2006; 52: 63-5.

17. Klein JO, Marcy SM. Bacterial septicaemia and meningitis. In: Remington JS, Klein JO, Eds. Infectious diseases of the fetus and newborn infants. $3^{\text {rd }}$ ed. Philadelphia: WB Saunders 1990: 601-56.

18. Vissers VE, Hall RT. Lumber puncture in the evaluation of suspected neonatal septicaemia. J Paediatr 1980; 96: 10637.

19. Wenger JD, Hightower AW, Facklam RR, Gaventa S, Broome $\mathrm{CV}$, Bacterial meningitis study group. Bacterial meningitis in the United States 1986: report of a multistate surveillance study. J Infect Dis 1990; 162: 1316-23.

20. Synnott MB, Morse DL, Hall SM. Neonatal meningitis in England and Wales: a review of routine national data. Arch Dis Child 1994; 71: 75-80.

21. Vesicari T, Janas M, Gronroos P, Tuppinainen N, Renlund M, Kero P, et al. Neonatal septicaemia. Arch Dis Child 1985; 60: 542-6. 
22. Glandstone IM, Ehrenkranz RA, Edberg SC, Baltimore RS. A ten-year review of neonatal sepsis and comparison with the previous fifty year experience. Paediat Infect Dis J 1990; 9: 819-25.

23. Bhutta ZA, Naqvi SH, Muzaffar T, Farooqui J. Neonatal sepsis in Pakistan: Presentation and pathogen. Acta Paediat Scand 1991; 80: 596-601.

24. Washburn TC, Medearis DN, Child B. Sex differences in susceptibility to infection. Paediatrics 1965; 35: 57-61.

25. Islam S. How safe is safe delivery. Bulletin of Commonwealth Association of Mental Handicap and Developmental Disabilities, 1991.

26. Akhter HH, Rahman MH, Mannan I, Elahi ME, Khan AKZ. Review of performance of trained TBAs. Dhaka: BIRPERHT, 1995.

27. Takkar VP, Bhakoo ON, Narang A. Scoring system for prediction of early neonatal infection. Ind Paediatr 1974; 11: 597-600.

28. Bang AT, Bang RA, Baitule SB, Reddy HM, Deshmukh MD. Management of Birth Asphyxia in Home Deliveries in Rural Gadchiroli: The Effect of Two Types of Birth Attendants and of Resuscitating with Mouth-to-Mouth, Tube-Mask or BagMask. J Perinatol 2005; 25: S82-S91.

29. Knudsen FJ, Steinrud J, Septicaemia of the newborn, associated with ruptured foetal membranes, discoloured amniotic fluid or maternal fever. Acta Paediat Scand 1976; 65: 725-30.

30. Haque KH. Infection and immunity in the newborn. In: Campbell AGM, Mcintosh N, editors. Forfor and Arneil's Textbook of Paediatrics (5 $5^{\text {th }}$ Edition). Edinburgh: Churchill Livingston 1998; pp. 273-89.

31. Haque KN, Chagia AH, Shaheed MM. Half a decade of neonatal sepsis, Riyadh, Saudi Arabia. J Trop Paediatr 1990; 36: $20-3$.

32. Squire E, Favara B, Todd J. Diagnosis of neonatal bacteriological infection, haematologic and pathologic findings in fatal and nonfatal cases. Paediatrics 1979; 64: 60-5.

33. Chow AW, Leake RD, Yamchi T, Anthony BF, Guze LB. Significance of anaerobes in neonatal bacteraemia: analysis of 23 cases and review of the literature. Paediatrics 1974; 54: 736-45.

34. Kapoor L, Randhawa VS, Deb M. Microbiological profile of neonatal septicemia in a pediatric care hospital in Delhi. J Commun Dis 2005; 37: 227-32.
35. Sharma PP, Halder D, Dutta A. Bacteriological profile of neonatal septicaemia. Ind Paediatr 1987; 11: 1010-7.

36. Mir F, Aman S, Khan SR. Neonatal sepsis. Review with a study of 50 cases. J Trop Paediatr 1987; 33: 131-5.

37. Ahmed SS, Chowdhury MAKA, Hoque MM, Ahmed ASMNU. Role of Intravenous Immunoglobulin (IVIG) as an Adjuvant in the Treatment of Neonatal Sepsis in Preterm Babies. Journal of Bangladesh College of Physicians and Surgeons 2006; 24: 97-104.

38. Bennhagen R, Svenningsen NW, Benassy AN. Changing pattern of neonatal meningitis in Sweden. Scand J Infect Dis 1987; 19: 587-93.

39. Robillard P-Y, Nabeth P, Hulsey TC, Sergent M-P, Pttrianin J, Janky E. Neonatal bacterial septicaemia in a tropical area. Four year experience in Guadeloupe (French West Indies). Acta Paediatr 1993; 82: 687-9.

40. WHO Young Infants Study Group. Bacterial aetiology of serious infections in young infants in developing countries: results of a multicenter study. Pediatr Infect Dis J 1999; 18 : S17-22.

41. Sáez-Llorens X, Ah-Chu MS, Castaño E, Cortés L, Torres A, Suárez M, et al. Intrapartum prophylaxis with Ceftriaxone decreases rates of bacterial colonization and early-onset infection in newborns. Clin Infect Dis 1995; 21: 876-80.

42. Walsh JA, Hutchins S. Group B streptococcal disease: its importance in the developing world and prospect for prevention with vaccines. Pediatr Infect Dis J 1989; 8: 2716.

43. Kuruvilla KA, Thomas N, Jesudasan MV, Jana AK. Neonatal group B streptococcal bacteraemia in India: ten years' experience. Acta Paediatr 1999; 88: 1031-2.

44. Nathoo KJ, Pazvakavamba I, Chidede OS, Chirisa C. Neonatal meningitis in Harare, Zimbabwe: a 2-year review. Ann Trop Paediatr 1991; 11: 11-5.

45. Dawodu AH, Damole IO, Onile BA. Epidemiology of group B streptococcal carriage among pregnant women and their neonates: an African experience. Trop Geogr Med 1983; 35: 145-50.

46. Ayata A, Guvene H, Felek S, et al. Maternal carriage and neonatal colonization of group B streptococci in labour are uncommon in Turkey. Paediatr Perinatal Epidemiol 1994; 8: 188-92.

47. Lakshmi V, Das S, Shivananda PG, Savitri P, Rao K. Incidence of group B beta haemolytic streptococci in the vaginal flora of pregnant women. Ind J Pathol Microbiol 1988; 31: 240-4. 